\title{
Creating functional nanostructures: Encapsulation of caffeine into $\alpha$-lactalbumin nanotubes
}

\author{
Clara Fuciños ${ }^{\mathrm{a}, \mathrm{b}, *}$, Martín Míguez ${ }^{\mathrm{a}}$, Pablo Fuciños ${ }^{\mathrm{c}}$, Lorenzo M. Pastrana ${ }^{\mathrm{c}}$, María L. Rúa ${ }^{\text {a }}$, António A. Vicente ${ }^{\mathrm{b}}$ \\ a Biotechnology Group, Department of Analytical Chemistry and Food Science, University of Vigo, As Lagoas s/n, 32004 Ourense, Spain \\ ${ }^{b}$ CEB - Centre of Biological Engineering, University of Minho, Campus de Gualtar s/n, 4710-057 Braga, Portugal \\ c The International Iberian Nanotechnology Laboratory (INL), Avenida Mestre José Veiga s/n, 4715-330 Braga, Portugal
}

\section{A R T I C L E I N F O}

\section{Article history:}

Received 21 February 2016

Received in revised form 27 June 2016

Accepted 29 July 2016

Available online 2 August 2016

Keywords:

Whey protein nanoparticles

Caffeine release

Encapsulation efficiency

Loading capacity

Nanostructures

Full factorial design

\begin{abstract}
A B S T R A C T
This work evaluated the stability and functionality of nanotubes obtained from $\alpha$-lactalbumin ( $\alpha$-LA). $\alpha$-LA nanotubes' structure was highly stable during a freeze-drying process but not after grinding. The ability of $\alpha$-LA nanotubes to encapsulate caffeine, used as a model molecule, was evaluated. $\alpha$-La nanotubes were highly effective for this purpose as encapsulation efficiency (\%EE) was near $100 \%$ and loading capacity (\%LC) near $10 \%$ at $1.5 / 20$ and $2 / 20$ ratios (caffeine/ $\alpha$-LA, $w / w$ ). $\alpha$-LA nanotubes' structure was not affected by the presence of caffeine. Also, in general, refrigeration temperatures and neutral or alkaline conditions, under which the adverse effect of chelating agents was prevented, helped to stabilise $\alpha$-LA nanotubes' structure and maintain caffeine encapsulated. At $8{ }^{\circ} \mathrm{C}$ and $\mathrm{pH} 7.5$, in the presence of $75 \mu \mathrm{g} \mathrm{mL} \mathrm{L}^{-1}$ of EDTA, $>50 \%$ of the caffeine remained encapsulated into $\alpha$-LA nanotubes.

Industrial relevance: Linear and hollow structures could be highly effective to increase the viscosity while encapsulating bioactive compounds to protect them from degradation, provide on-demand release, or mask unpleasant organoleptic properties. However, until now, carbon nanotubes are the most commonly used carriers for the controlled release of bioactive molecules and these are not food-grade materials. Enzymatic partial hydrolysis of $\alpha$-lactalbumin ( $\alpha$-LA) in the presence of a divalent ion results in the formation of food-grade nanotubes with high potential in the food and cosmetic industry. In this work the functionality of $\alpha$-LA nanotubes was evaluated considering their applicability in real food.
\end{abstract}

(C) 2016 Elsevier Ltd. All rights reserved.

\section{Introduction}

The addition of ingredients with functional properties into food products allows developing new functional foods. However, some factors can limit their application. The bioavailability of these compounds depends on their stability under conditions that can occur in foods during processing or in the gastro-intestinal (GI) tract (Chen, Remondetto, \& Subirade, 2006; Chen \& Subirade, 2007). Besides, many ingredients used in the food industry have an unpleasant flavour that should be masked (Nedovic, Kalusevic, Manojlovic, Petrovic, \& Bugarski, 2013), as is the case of caffeine (MW: $194.19 \mathrm{~g} \mathrm{~mol}^{-1}$ ). Caffeine is commonly used as an active component of energy drinks due to its many effects on the central nervous system, reducing drowsiness, and restoring concentration (Belscak-Cvitanovic et al., 2015). Although many people desire these benefits of caffeine, not everyone likes the characteristic bitterness associated with caffeine. This fact limits the use of caffeine in certain food applications or involves adding sugars and flavours to mask the bitterness

\footnotetext{
* Corresponding author at: Biotechnology Group, Department of Analytical Chemistry and Food Science, University of Vigo, As Lagoas s/n, 32004 Ourense, Spain.

E-mail address: clarafg@gmail.com (C. Fuciños).
}

(Sobel, Gundlach, \& Su, 2014). Encapsulation can provide healthier technological solutions to these problems by preventing caffeine release into the food and allowing it into the gastrointestinal tract, avoiding sugar addition usually added to masking the bitter taste of caffeine (Belscak-Cvitanovic et al., 2015; Bohannon, 2008; Gunasekaran, Ko, \& Xiao, 2007; Madadlou, Jaberipour, \& Eskandari, 2014; Nedovic et al., 2013). Also, the controlled release of caffeine once ingested will allow those people with caffeine sensibility to reduce gastrointestinal problems associated with the ingestion of high amounts of caffeine (Gudas et al., 2000). Besides caffeine absorption from the gastrointestinal tract is too rapid (Belscak-Cvitanovic et al., 2015), so controlling its release after ingestion may be beneficial for food and nutraceutical applications maintaining its positive effects for a longer time, in the same way as the controlled release of other bioactive compounds.

A large number of delivery systems for medical and pharmaceutical applications have been developed using different biopolymers (Dumitriu \& Popa, 2013; Langer \& Peppas, 2003). However, the application here addressed needs materials considered as GRAS (Generally Recognised as Safe). In this regard, food biopolymers, specifically food proteins, are widely used due to their high nutritional value and functional properties. These features include their ability to form gels and 
emulsions, their availability from abundant renewable sources, and their acceptability as naturally occurring food components (Chen \& Subirade, 2007; Chen et al., 2006; Mohammadi, Jafari, Esfanjani, \& Akhavan, 2016). $\alpha$-Lactalbumin ( $\alpha$-LA) from cheese whey, a byproduct of the cheese industry, has a high nutritional and functional value. Besides, it can self-assemble into nanotube structures that could be used to modify food texture and to encapsulate micronutrients.

Whey protein nanotubes can be formed by partial hydrolysis of $\alpha$ lactalbumin ( $\alpha$-LA). The reaction is catalysed by a serine endoprotease from Bacillus licheniformis (BLP) in the presence of a divalent cation, which promotes the formation of salt-bridges between two deionized carboxylic groups (Graveland-Bikker, Ipsen, Otte, \& De Kruif, 2004; Ipsen \& Otte, 2007). The type and concentration of cation and the reaction temperature will determine the correct nanotube formation with around $20 \mathrm{~nm}$ in outer diameter and $7 \mathrm{~nm}$ in inner diameter (Graveland-Bikker et al., 2004).

Decreasing the particle size of food ingredients increases their surface area improving their solubility, dispersion and therefore their delivery properties as improves their availability and absorption (Abbasi, Emam-Djomeh, Mousavi, \& Davoodi, 2014; Augustin, 2003; Chen et al. 2006; López-Rubio \& Lagaron, 2012). Particle size reduction also improves the sensory properties (extends flavour perception, provides better mouth feel, transparent appearance), and enhances the processability (Bagheri, Madadlou, Yarmand, \& Mousavi, 2013; Moraru et al., 2003). Smaller sizes also increase the adhesiveness and extend the GI transit time, leading to a higher drug bioavailability (Chen et al., 2006).

Additionally, proteins nanotubes have advantages over other protein structures that make them more suitable to transport and release different bioactive compounds (Graveland-Bikker, 2005; Ipsen \& Otte, 2007; Sadeghi et al., 2013). Their open ends, on both sides of the tubes, may provide a more efficient delivery and controlled release of bioactive compounds. Besides, as both outer and inner layers of nanotubes have different chemical characteristics, they could be functionalized differently, for example immobilising various bioactive compounds on both sides. Once encapsulated, bioactive compounds could be released from nanotubes in a controlled manner taking advantage of the ability of $\alpha$-LA nanotubes to disassemble by lowering the $\mathrm{pH}$ below 3 , which may be exploited for the transport and controlled release of bioactive compounds to specified sites of the GI tract. Besides all these advantages, tubular nanostructures could be very useful as thickener agents as structures with linear alignment are highly efficient to improve viscosity.

Despite the interesting properties of protein nanotubes and their potential as delivery structures, to our knowledge, only Sadeghi et al. (2013) described the application of BSA nanotubes to incorporate curcumin as a bioactive compound.

On the other hand, commercialization of $\alpha$-LA nanotubes in solution is not possible because they could be contaminated or degraded. For this reason, $\alpha$-LA nanotubes should be dried to improve their marketability and stability during storage. We propose two steps to obtain a dry powder of $\alpha$-LA nanotubes: freeze-drying followed by a grinding process. $\alpha$-LA nanotubes resistance to a freeze-drying process has already been tested in a previous work (Graveland-Bikker, 2005). However, to our knowledge, the effect of grinding on $\alpha$-LA nanotubes has never been studied.

In this work were evaluated $\alpha$-LA nanotubes' physical stability and their functional ability by determining their capacity and effectiveness to encapsulate caffeine and retain it under environmental conditions commonly found in food products, which may compromise $\alpha$-LA nanotubes' chemical stability.

\section{Materials and methods}

\subsection{Standards and chemicals}

$\alpha$-LA ( $\alpha$-lactalbumin) was gently supplied by Davisco Foods International, Inc. (Eden Prairie, MN, USA). Trifluoroacetic acid
CHROMASOLV®, for HPLC (TFA, $\geq 99.0 \%$ ), acetonitrile CHROMASOLV® Plus, for HPLC (ACN, $\geq 99.9 \%$ ), ethylenediaminetetraacetic acid (EDTA, 99.4-100.6\%), piperazine (anhydrous, $\geq 99.0 \%$ ), 3-( $N$-Morpholino) propanesulfonic acid (MOPS, $\geq 99.5 \%$ ) and sodium chloride $(\mathrm{NaCl})$ were purchased from Sigma-Aldrich (Munich, Germany). TRIS buffer (tris-(hydroxymethyl)-aminomethane, extra pure) was from Scharlau. Hydrochloric acid $(\mathrm{HCl}, 37 \%)$, sodium hydroxide $(\mathrm{NaOH})$ and Glycine were from Panreac (Barcelona, Spain). Serine protease from Bacillus licheniformis (BLP) was gently supplied by Novozymes A/S (Bagsværd, Denmark). Manganese (II) chloride tetrahydrate $\left(\mathrm{MnCl}_{2} \cdot 4 \mathrm{H}_{2} \mathrm{O}\right)$ was from Merck (Darmstadt, Germany). Sodium cacodylate EM and glutaraldehyde EM 25\%, were purchased from TAAB (Reading, UK). Caffeine anhydrous was purchased from VWR (Pennsylvania, US).

\subsection{Nanotube synthesis}

Nanotubes were prepared following the method described in Graveland-Bikker et al. (2004) with some modifications. Briefly, for all the assays, the $\alpha$-LA powder was dissolved $\left(30 \mathrm{~g} \mathrm{~L}^{-1}\right.$ ) in buffer $75 \mathrm{mM}$ Tris- $\mathrm{HCl}$ ( $\mathrm{pH}$ 7.5). $\mathrm{MnCl}_{2} \cdot 4 \mathrm{H}_{2} \mathrm{O}$ was added to the $\alpha$-LA solution to obtain the final desired concentration of $\mathrm{Mn}^{2+}(R=2 \mathrm{~mol}$ of ion $/ \mathrm{mol}$ of $\alpha$-LA). To begin the hydrolysis, $4 \% \operatorname{BLP}(w / w)$, respect to the amount of protein sample, was added. After stirring, the solution was immediately filtered using a $0.1 \mu \mathrm{m}$ low protein binding filter from Millipore Ibérica, S.A. (Madrid, Spain) and incubated at $55^{\circ} \mathrm{C}$ in a thermostatic bath for $3 \mathrm{~h}$.

According to previous works (Gunasekaran et al., 2007; Madadlou et al., 2014) caffeine does not bind with whey proteins, so apparently encapsulation was only due to physical entrapment. Thus, caffeineloaded nanotubes were prepared by adding caffeine to the reaction before the nanotube formation to be trapped during self-assembly. The binding constant of caffeine with manganese is very low (Kolayli, Ocak, Küçük, \& Abbasoglu, 2004), so chelating capacity at the concentrations of caffeine used is negligible.

The desired amount of caffeine was added to the $\alpha$-LA solution in Tris- $\mathrm{HCl} 75 \mathrm{mM}$ ( $\mathrm{pH} 7.5$ ) with $\mathrm{MnCl}_{2} \cdot 4 \mathrm{H}_{2} \mathrm{O}$ before adding the BLP so that caffeine was trapped inside during nanotubes' self-assembly. Six caffeine $/ \alpha$-LA $(w / w)$ ratios have been tested: $0 / 20,0.2 / 20,1 / 20$, $1.5 / 20,2 / 20$, and $4 / 20$.

\subsection{Determination of nanotubes' physical stability}

To determine the stability of $\alpha$-LA nanotubes, under two common industrial processes such as freeze-drying and grinding, $\alpha$-LA nanotubes samples were immediately frozen at $-80{ }^{\circ} \mathrm{C}$ after their synthesis and then freeze dried. Once the samples were freeze-dried, they were resuspended in the same volume of buffer $75 \mathrm{mM}$ Tris- $\mathrm{HCl}(\mathrm{pH} 7.5)$ used during their synthesis. From each sample, a $25 \mu \mathrm{L}$ aliquot was withdrawn and analysed by TEM. Three replicates were analysed for each condition.

Grinding resistance was examined using freeze-dried nanotubes prepared as explain in the above paragraph. Glass beads (425-600 $\mu \mathrm{m}$ acid washed glass beads, Sigma-Aldrich) were added to the freezedried nanotube samples in a relation 1:1 $(w / w)$. Samples were then shaken in a Tissuelyser ${ }^{\circledR}$ LT (Qiagen, Venlo, The Netherlands) for $3 \mathrm{~min}$ at $32.5 \mathrm{~Hz}$. Finally, samples were resuspended in the same volume of buffer $75 \mathrm{mM}$ Tris- $\mathrm{HCl}$ ( $\mathrm{pH} 7.5$ ) used during their synthesis. From each sample, a $25 \mu \mathrm{L}$ aliquot was withdrawn and analysed by TEM. Three replicates were analysed for each condition.

\subsection{Determination of encapsulation efficiency and loading capacity}

Encapsulation efficiency (\%EE) and loading capacity (\%LC) were determined by filtration separating the caffeine-loaded nanotubes from the supernatant containing free caffeine by filtration. The procedure was as follows. Once caffeine-loaded nanotube samples were obtained 
as explained above, $8 \mathrm{~mL}$ of $75 \mathrm{mM}$ Tris- $\mathrm{HCl}$ buffer $\left(\mathrm{pH} 7.5\right.$ at $25^{\circ} \mathrm{C}$ ) were added to $2 \mathrm{~mL}$ of nanotube samples. Then samples were subjected to a gentle shaking (favouring sample washing without damaging the nanotube structure) for periods of $15 \mathrm{~min}$ in a rocking shaker. At different time intervals, shaking was stopped, and $1 \mathrm{~mL}$ of the supernatant was removed and filtered through a $0.2 \mu \mathrm{m}$ filter. Supernatant aliquots were stored at $-20{ }^{\circ} \mathrm{C}$ until caffeine quantification by RP-HPLC. Three replicates were analysed for each condition.

$\% E E$ and \%LC were calculated as follows:

$\% E E=\frac{\mathrm{Caf}_{\text {total }}-\mathrm{Caf}_{\text {free }}}{C a f_{\text {total }}} \times 100$

$\% L C=\frac{C a f_{\text {total }}-C a f_{\text {free }}}{\alpha-L A_{\text {total }}} \times 100$

where $C a f_{\text {total }}$ is the total amount of caffeine initially added to the reaction to be incorporated into nanotubes during their synthesis, $C a f_{\text {free }}$ is the amount of free caffeine determined in the filtrated supernatant. $\alpha$ $L A_{\text {total }}$ is the amount of $\alpha$-LA employed for nanotube synthesis.

\subsection{Determination of nanotubes' disassembly and caffeine release}

Ideally, caffeine would remain protected into the nanotubes when it is added to food products. Therefore, nanotube stability and caffeine release was studied under different environmental conditions that may occur in food products.

For that purpose, we studied temperatures from refrigeration till pasteurization $\left(8-80^{\circ} \mathrm{C}\right), \mathrm{pH}$ values from 2 to 8 , the presence of chelating agent (EDTA, usually added as antioxidant agent at maximum concentrations of $75 \mu \mathrm{g} \mathrm{mL} \mathrm{L}^{-1}$ ), and the addition of salt ( $\mathrm{NaCl}$, usually added as preservative and flavouring at concentrations around $1000 \mu \mathrm{g} \mathrm{mL}{ }^{-1}$ ).

A $2^{4}$ full-factorial design (Box, Hunter, and Hunter $2^{\mathrm{K}-\mathrm{p}}$ type) was used to analysed the effect of the four variables above exposed (T, $\mathrm{pH}$, EDTA, $\mathrm{NaCl}$ ) on the nanotube disassembly and caffeine release. For each experiment of the design, caffeine release kinetics were performed by adding $1.5 \mathrm{~mL}$ of the corresponding buffer, indicated in Table 1, over $0.380 \mathrm{~mL}$ of caffeine-loaded nanotubes prepared with a caffeine $/ \alpha$-LA ratio of 1.5/20 (w/w). $\alpha$-LA nanotubes samples without caffeine were also evaluated in the same way to be used as controls. Samples were then incubated in a thermostatic bath at the temperatures indicated in
Table 1. One sample was prepared for each sampling time. The supernatants were filtered through $0.2 \mu \mathrm{m}$ filters and aliquots were stored at $-20{ }^{\circ} \mathrm{C}$ until caffeine quantification by RP-HPLC. TEM analyses were performed with $25 \mu \mathrm{L}$ aliquots removed from the samples at the end of the assay.

The percentage of free caffeine released from nanotubes (\%Caf free) was calculated as follows:

$\%$ Caf $f_{\text {free }}=\frac{\operatorname{Caf}_{\text {free }}}{\text { Caf }_{\text {total }}} \times 100$

where $\mathrm{Caf}_{\text {total }}$ is the total amount of caffeine initially added to the reaction for incorporation into the nanotubes during their synthesis, and $\mathrm{Caf}_{\text {free }}$ is the amount of free caffeine determined in the filtered supernatant.

The maximum percentage of free caffeine released from nanotubes (\% Caf free max $)$ was evaluated as the dependent variable in the factorial design and calculated by fitting the experimental data with the following equation (Fuciños et al., 2012):

$\%$ Caf $f_{\text {free } t}=\% \operatorname{Caf}_{\text {free } \max }+\left(\% C a f_{\text {free } 0}-\% C a f_{\text {free max }}\right) e^{-m \cdot t}$

where $\% \mathrm{Caf}_{\text {free } 0}$ and $\% \mathrm{Caf} f_{\text {free } t}$ are the percentages of free caffeine released from nanotubes at the initial time and at time $t$, calculated with Eq. (3) for each sampling time. The parameter $m\left(h^{-1}\right)$ is the maximum release rate, and $t(\mathrm{~h})$ is the sampling time.

The full-factorial design consisted in 20 experiments with 16 factorial points $\left(2^{4}\right)$ and four central points for replication. The range and codification of the independent variables are shown in Table 1.

Statistical analysis was performed using Statistica 8.0 (StatSoft, Inc.). Response values from the experiments of the factorial design were fitted to the following polynomial linear model:

$$
\begin{aligned}
y= & \alpha_{0}+\alpha_{1} \cdot X_{1}+\alpha_{2} \cdot X_{2}+\alpha_{3} \cdot X_{3}+\alpha_{4} \cdot X_{4}+\alpha_{12} \cdot X_{1} \cdot X_{2}+\alpha_{13} \cdot X_{1} \cdot X_{3} \\
& +\alpha_{14} \cdot X_{1} \cdot X_{4}+\alpha_{23} \cdot X_{2} \cdot X_{3}+\alpha_{24} \cdot X_{2} \cdot X_{4}+\alpha_{34} \cdot X_{3} \cdot X_{4} \\
& +\alpha_{123} \cdot X_{1} \cdot X_{2} \cdot X_{3}+\alpha_{124} \cdot X_{1} \cdot X_{2} \cdot X_{4}+\alpha_{134} \cdot X_{1} \cdot X_{3} \cdot X_{4} \\
& +\alpha_{234} \cdot X_{2} \cdot X_{3} \cdot X_{4}
\end{aligned}
$$

where $y$ is the response $\left(\% C a f_{f r e e ~ m a x}\right) . X_{1}, X_{2}, X_{3}$, and $X_{4}$ are the coded levels of the independent factors, i.e. temperature (T), pH, the concentration of EDTA (EDTA) and the concentration of $\mathrm{NaCl}(\mathrm{NaCl})$, respec-

\begin{tabular}{|c|c|c|c|c|c|c|c|c|c|}
\hline \multicolumn{4}{|c|}{ Coded values } & \multicolumn{4}{|c|}{ Natural values } & \multirow{2}{*}{$\frac{\text { Responses }}{\% \text { Caf free max }}$} & \multirow[t]{2}{*}{ Buffer (75 mM) } \\
\hline $\mathrm{T}$ & $\mathrm{pH}$ & EDTA & $\mathrm{NaCl}$ & $\mathrm{T}\left({ }^{\circ} \mathrm{C}\right)$ & $\mathrm{pH}$ & $\operatorname{EDTA}\left(\mu \mathrm{g} \mathrm{mL}{ }^{-1}\right)$ & $\mathrm{NaCl}\left(\mu \mathrm{g} \mathrm{mL}^{-1}\right)$ & & \\
\hline-1 & -1 & -1 & -1 & 8 & 2.0 & 0.0 & 0.0 & $67.41 \pm 9.30$ & Glycine-HCl \\
\hline 1 & -1 & -1 & -1 & 80 & 2.0 & 0.0 & 0.0 & $104.30 \pm 9.85$ & Glycine-HCl \\
\hline-1 & 1 & -1 & -1 & 8 & 7.5 & 0.0 & 0.0 & $56.78 \pm 5.00$ & MOPS-NaOH \\
\hline 1 & 1 & -1 & -1 & 80 & 7.5 & 0.0 & 0.0 & $79.68 \pm 3.84$ & Piperazine- $\mathrm{HCl}$ \\
\hline-1 & -1 & 1 & -1 & 8 & 2.0 & 75.0 & 0.0 & $88.44 \pm 17.97$ & Glycine- $\mathrm{HCl}$ \\
\hline 1 & -1 & 1 & -1 & 80 & 2.0 & 75.0 & 0.0 & $85.28 \pm 1.33$ & Glycine- $\mathrm{HCl}$ \\
\hline-1 & 1 & 1 & -1 & 8 & 7.5 & 75.0 & 0.0 & $45.42 \pm 3.73$ & MOPS-NaOH \\
\hline 1 & 1 & 1 & -1 & 80 & 7.5 & 75.0 & 0.0 & $79.12 \pm 9.09$ & Piperazine- $\mathrm{HCl}$ \\
\hline-1 & -1 & -1 & 1 & 8 & 2.0 & 0.0 & 1000 & $61.61 \pm 3.62$ & Glycine- $\mathrm{HCl}$ \\
\hline 1 & -1 & -1 & 1 & 80 & 2,0 & 0,0 & 1000 & $101.80 \pm 3.90$ & Glycine-HCl \\
\hline-1 & 1 & -1 & 1 & 8 & 7.5 & 0.0 & 1000 & $42.85 \pm 3.40$ & MOPS-NaOH \\
\hline 1 & 1 & -1 & 1 & 80 & 7.5 & 0.0 & 1000 & $94.41 \pm 4.75$ & Piperazine- $\mathrm{HCl}$ \\
\hline-1 & -1 & 1 & 1 & 8 & 2.0 & 75.0 & 1000 & $128.8 \pm 41.61$ & Glycine- $\mathrm{HCl}$ \\
\hline 1 & -1 & 1 & 1 & 80 & 2.0 & 75.0 & 1000 & $95.91 \pm 4.55$ & Glycine-HCl \\
\hline-1 & 1 & 1 & 1 & 8 & 7.5 & 75.0 & 1000 & $47.83 \pm 3.57$ & MOPS-NaOH \\
\hline 1 & 1 & 1 & 1 & 80 & 7.5 & 75.0 & 1000 & $87.17 \pm 0.77$ & Piperazine- $\mathrm{HCl}$ \\
\hline 0 & 0 & 0 & 0 & 44 & 4.8 & 37.5 & 500 & $70.28 \pm 9.77$ & Piperazine- $\mathrm{HCl}$ \\
\hline 0 & 0 & 0 & 0 & 44 & 4.8 & 37.5 & 500 & $87.26 \pm 9.98$ & Piperazine- $\mathrm{HCl}$ \\
\hline 0 & 0 & 0 & 0 & 44 & 4.8 & 37.5 & 500 & $76.89 \pm 6.44$ & Piperazine- $\mathrm{HCl}$ \\
\hline 0 & 0 & 0 & 0 & 44 & 4.8 & 37.5 & 500 & $85.78 \pm 10.18$ & Piperazine- $\mathrm{HCl}$ \\
\hline
\end{tabular}
tively. $X_{1} \cdot X_{2}$ to $X_{2} \cdot X_{3} \cdot X_{4}$ represent the interaction terms. $\alpha_{0}$ is the

Table 1

Range and codification criterion for independent variables in the fractional factorial design at 2 levels (Box, Hunter, and Hunter $2^{4}$ type, $R=$ FULL). 
independent term. $\alpha_{1}$ to $\alpha_{234}$ are the regression coefficients of factors and interaction terms. The objective function in this study was that which minimises the \% $\mathrm{Caf}_{\text {free max }}$ by investigating its relationship with the factors mentioned above. The signification of coefficients for the model, and the model adequacy was analysed by an Analysis of Variance (ANOVA).

2.6. Protein profile analysis and caffeine quantification by reverse-phase high-performance liquid chromatography

The determination of the profile of $\alpha$-LA fragments that appear during nanotube disassembly and the caffeine quantification were performed by RP-HPLC following the method described by Estévez (2015). Briefly, the separation was performed employing an ACE® C18 column $(4.6 \mathrm{~mm} \times 250 \mathrm{~mm}, 5 \mu \mathrm{m}, 300 \AA)$ at $30^{\circ} \mathrm{C}$. The flow rate was $0.7 \mathrm{~mL} \mathrm{~min}^{-1}$, the injection volume was $20 \mu \mathrm{L}$ and the detection wavelength $220 \mathrm{~nm}$. Mobile phase A was $0.1 \%(v / v)$ TFA in Milli-Q water, and mobile phase B was $0.1 \%(v / v)$ TFA in $100 \%(v / v)$ ACN. Mobile phase $A$ was maintained at $100 \%$ for $5 \mathrm{~min}$, then it decreased linearly to $50 \%$ over $50 \mathrm{~min}$. Mobile phase B was increased linearly to $100 \%$ over the next 2.5 min and then was maintained at $100 \%$ of mobile phase B for another 2.5 min. Finally, mobile phase A was increased linearly to $100 \%$ over $5 \mathrm{~min}$ and the column was re-equilibrated at $100 \%$ of mobile phase $A$ for a further 5 min.

A commercial standard of $\alpha$-LA was used to determine its retention time. Calibration curves of caffeine were constructed the commercial standard, which resulted highly linear within the concentration range 0.01-1 $\mathrm{mg} \mathrm{mL}^{-1}$. All the analysis were performed in triplicate.

\subsection{Transmission electron microscopy (TEM)}

$\alpha$-La nanotube samples were 1:1 diluted with fixative (1.5\% glutaraldehyde in $0.1 \mathrm{M}$ sodium cacodylate buffer) and stored at $4{ }^{\circ} \mathrm{C}$ until their analysis. Samples were prepared by the conventional negative staining method. A Formvar layer on a copper grid was coated with carbon, immersed in $5 \mu \mathrm{L}$ of the sample $2 \times$ ( samples from physical stability and encapsulation efficiency and loading capacity) and $1 \times$ (samples from nanotubes' disassembly and caffeine release kinetics) diluted, and blotted after $1 \mathrm{~min}$. Then, the copper grid was washed with water for $1 \mathrm{~min}$ and subsequently blotted, to remove the excess of protein material. After that, the copper grid was immersed in 3\% ( $w / w)$ uranyl acetate, to enhance the contrast, during $1 \mathrm{~min}$ and blotted again. Samples were then dried for $1 \mathrm{~h}$ in a desiccator. Micrographs were obtained with a JEOL JEM-1010 $100 \mathrm{kV}$ high contrast transmission electron microscope (CACTI, University of Vigo, Spain).

\section{Results and discussion}

\subsection{Nanotubes' physical stability}

To commercialise $\alpha$-LA nanotubes as a dry powder, the stability of $\alpha$-LA nanotubes was evaluated under industrial processing conditions, such as freeze-drying and grinding. $\alpha$-LA nanotubes were frozen and freeze-dried after their synthesis. Fig. 1 shows TEM micrographs of redispersed freeze-dried nanotubes in the synthesis buffer. Nanotubes' structures resisted the freeze-drying process without significant morphological changes. These results are in agreement with those obtained by Graveland-Bikker (2005) with $\alpha$-LA nanotubes synthesised in the presence of calcium, suggesting that the type of cation does not affect the mechanical resistance of structures under mild stress conditions. However, intense mechanical stress, at which the nanotube samples were subjected during grinding, destroyed their original tubular structure (Fig. 1).

\subsection{Encapsulation efficiency and loading capacity}

The ability of $\alpha$-LA nanotubes to encapsulate caffeine, used as a model molecule, was evaluated through the determination of encapsulation efficiency (\%EE) and loading capacity (\%LC). At low caffeine/ $\alpha$-LA ratios $(w / w)$ we could not detect caffeine encapsulation (Fig. 2). However, nanotubes seem to be highly effective in caffeine encapsulation at $1.5 / 20$ and $2 / 20$ ratios, as \%EE was near $100 \%$ ( $96.96 \pm 2.12 \%$ and $97.16 \pm 1.91 \%$, respectively) and \%LC was around $10 \%(9.21 \pm 0.20 \%$ and $12.30 \pm 0.24 \%$, respectively) (Fig. 2). High concentrations of polymer and bioactive compound increase the encapsulation efficiency as low levels may decrease the contact between the polymer and the bioactive compound. So, increasing the bioactive compound/polymer ratio could result in an encapsulation increase although the encapsulation efficiency may decrease at higher ratios (Pridgen, Alexis, Langer, \& Farohkzad, 2009). In fact, the growth in caffeine $/ \alpha$-LA ratio led to higher $\% L C$, but \%EE rose until reaching a plateau of which the growth in caffeine $/ \alpha$-LA ratio resulted in a \%EE decrease. This behaviour could be explained by considering that caffeine-coupling sites into nanotubes are limited. At high caffeine $/ \alpha$-LA ratios, coupling sites were less available, so encapsulation was less efficient. Indeed, prolonged washing times (60 min) promoted caffeine decapsulation at the highest caffeine $/ \alpha$-LA ratio assayed, at which nanotubes coupling sites could be saturated and not bound caffeine could be more easily released. For this reason, a compromise caffeine/ $\alpha$-LA ratio must be achieved such that \%EE was higher enough without caffeine decapsulation when
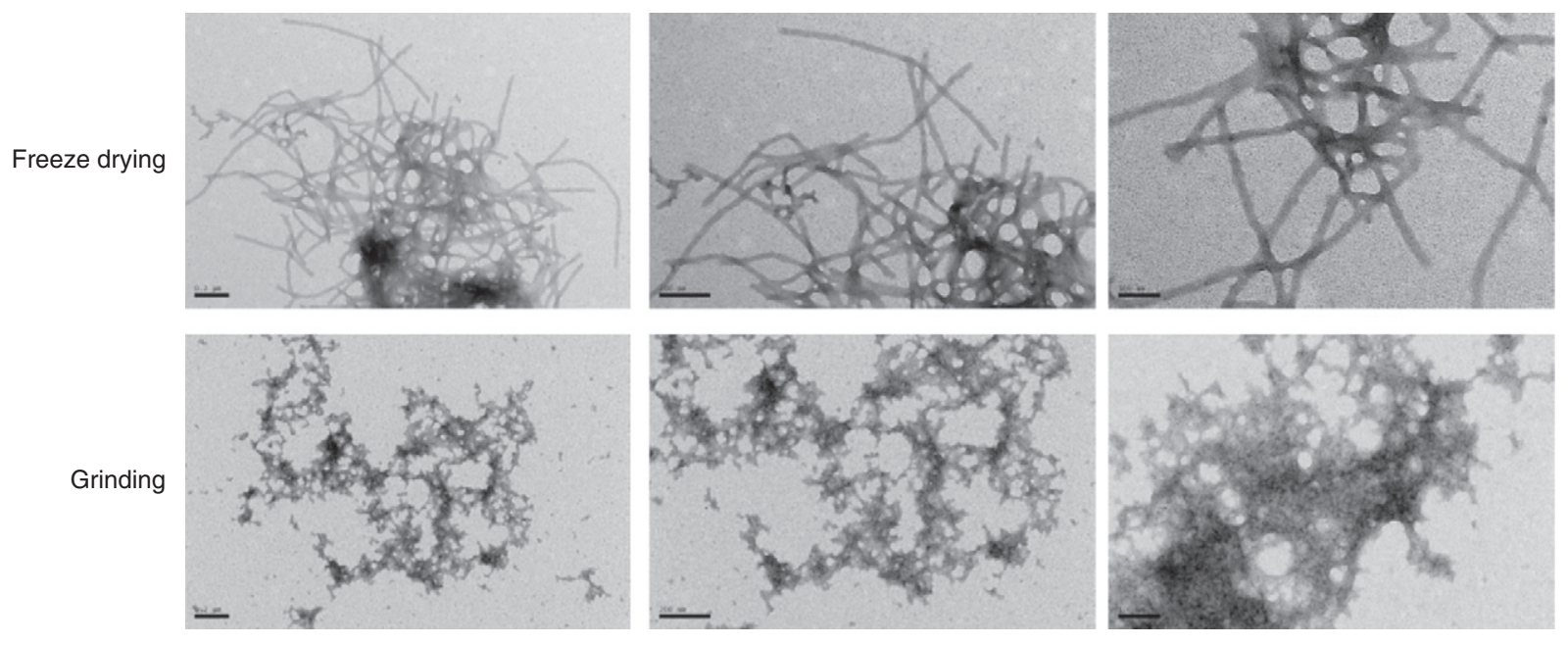

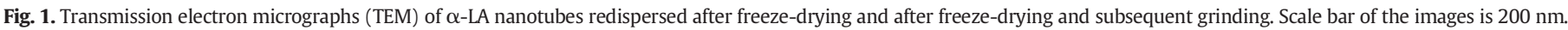



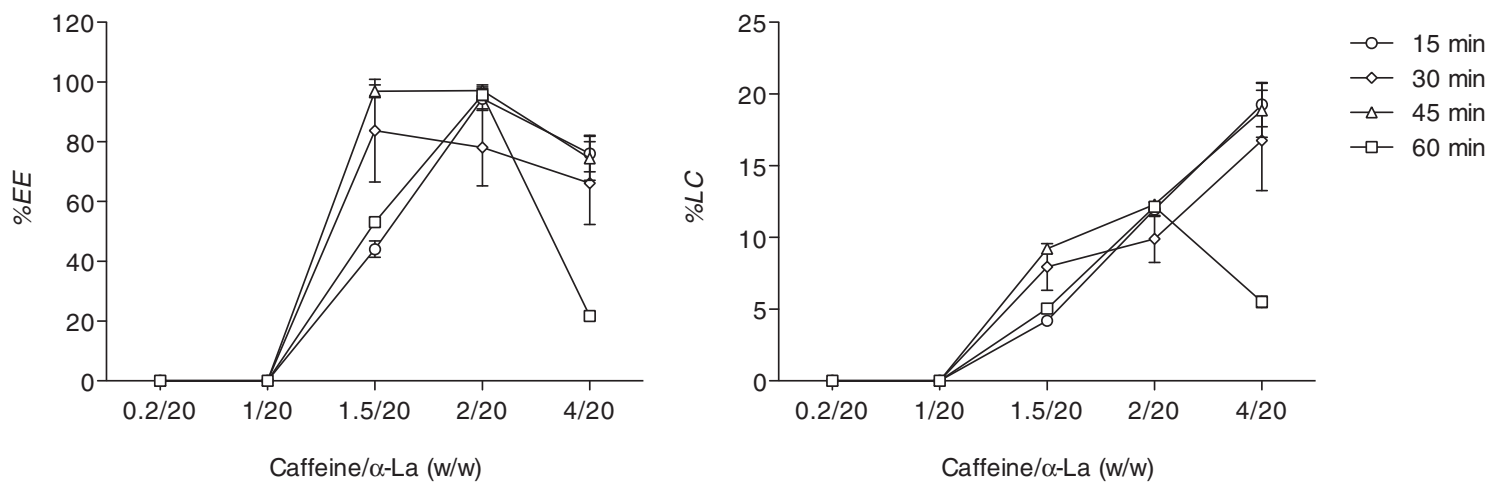

Fig. 2. Encapsulation efficiency (\%EE) and loading capacity (\%LC) of $\alpha$-LA nanotubes synthesised in the presence of different ratios of caffeine/ $\alpha$-LA and after different washing times.

nanotubes remain in suspension for a long time, for example in liquid food products.

TEM micrographs (Fig. 3), taken just after caffeine-loaded nanotube synthesis, agree with the results described above. Up to the ratio $1.5 / 20$, the structure of nanotubes appeared intact. However, at higher ratios nanotubes' surface seem to be modified by the presence of free caffeine. At the ratio $2 / 20, \alpha$-LA nanotubes showed a sort of coating, which blurs nanotubes' surface. At the ratio $4 / 20$, nanotubes probably already exist

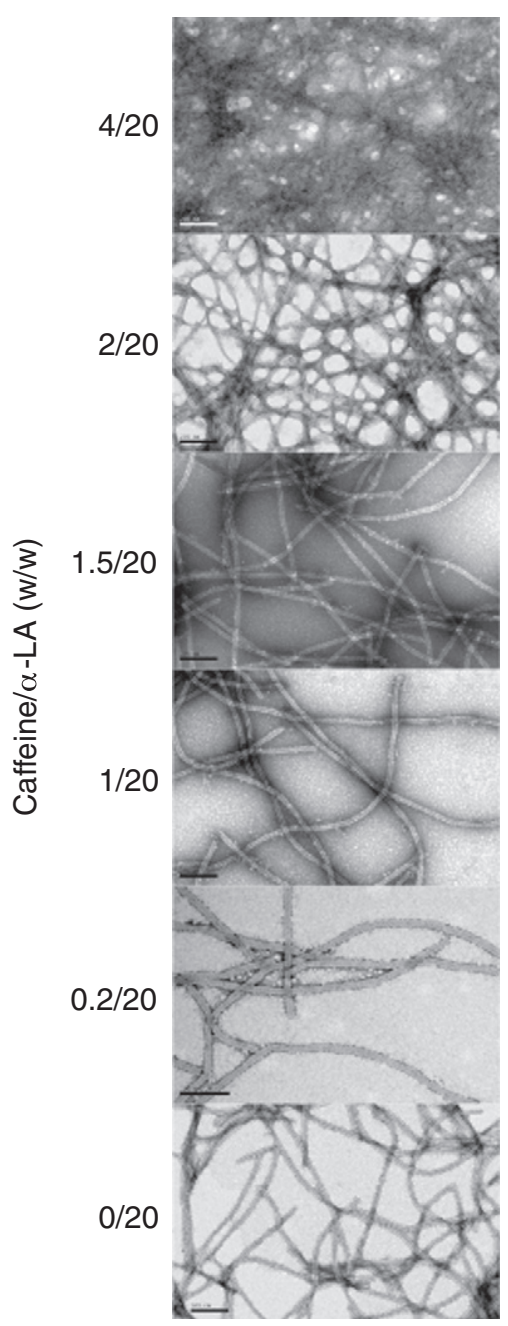

Fig. 3. Transmission electron micrographs (TEM) of caffeine-loaded $\alpha$-LA nanotubes at different relations of caffeine $/ \alpha$-LA. Scale bar of the images is $200 \mathrm{~nm}$. but can no longer be identified due to the presence of a large amount of free caffeine on their surface, which could be easily released to the liquid medium in which the nanotubes were incorporated.

The values of \%EE obtained with $\alpha$-LA nanotubes were higher than those achieved by caffeine encapsulation into other biopolymer nanoparticles, like the alginate nanoparticles with around 85\% EE (Bagheri et al., 2013), or lactoferrin-glycomacropeptide nanohydrogels with around 90\% EE (Bourbon, Cerqueira, \& Vicente, 2016). This fact is even more evident when the results obtained here are compared with those obtained when other bioactive compounds, different from caffeine, were encapsulated in whey protein nanostructures. For example, the $70-80 \%$ EE reached by metoprolol succinate encapsulation into $\alpha$-LA microparticles (Vijayaragavan et al., 2014), the 55\% EE obtained by anthocyanin extract (Arroyo-Maya et al., 2012) or the encapsulation of date palm pit aqueous extract into WPI nanoparticles (Bagheri et al., 2013).

\subsection{Nanotubes' disassembly and caffeine release}

To evaluate how different environmental factors, that may occur in food products, could affect nanotube stability, a full $2^{4}$ full-factorial design was performed using as independent variables temperature $\left(8-80{ }^{\circ} \mathrm{C}\right), \mathrm{pH}(2-8)$, EDTA concentration $\left(0-75 \mu \mathrm{g} \mathrm{mL}{ }^{-1}\right)$, and $\mathrm{NaCl}$ $\left(0-1000 \mu \mathrm{g} \mathrm{mL}{ }^{-1}\right)$.

The maximum percentage of caffeine released from $\alpha$-LA nanotubes $(\%$ Caf free max $)$, obtained by fitting experimental release kinetics for each experiment of the factorial design (data not shown) to the Eq. (4), ranged from $40 \%$ to $100 \%$ (Table 1 ).

Fig. 4 showed TEM micrographs and RP-HPLC chromatograms of samples under those conditions which hindered the lowest and the highest caffeine release (Table 1). Both micrographs and chromatograms showed a strong correlation with the \%Caf free max values. Conditions in which the release was low were those corresponding to intact or less degraded nanotubes in TEM micrographs ( $A$ and $B$ ). The absence of the characteristic peak of $\alpha$-LA at around 55 min indicates that there were no free $\alpha$-LA fragments in solution, evidencing that it was still part of the nanotube's structure. Conversely, conditions in which caffeine release was high were those corresponding to nanotubes that appeared more degraded in TEM micrographs ( $C$ and $\mathrm{D}$ ). Accordingly, peaks associated with large fragments of $\alpha$-LA appeared in the RP-HPLC chromatograms.

Mathematical modelling of the $2^{4}$ full-factorial design data was carried out using Eq. (5) to obtain a polynomial empirical model. Coded values of the independent variables $\left(\mathrm{T},{ }^{\circ} \mathrm{C}\right.$; $\mathrm{pH}$; EDTA, $\mu \mathrm{g} \mathrm{mL}{ }^{-1}$; and $\mathrm{NaCl}, \mu \mathrm{g} \mathrm{mL}^{-1}$ ) and their products, as shown in Eq. (5), along with the dependent variable (\%Caf free max ) were subjected to multiple regression analysis to determine the coefficients $\left(\alpha_{1}\right.$ to $\left.\alpha_{234}\right)$ and $p$-values of each term of the equation. An analysis of variance was performed to determine which factors significantly affected the \%Caf free max (Table 2). 


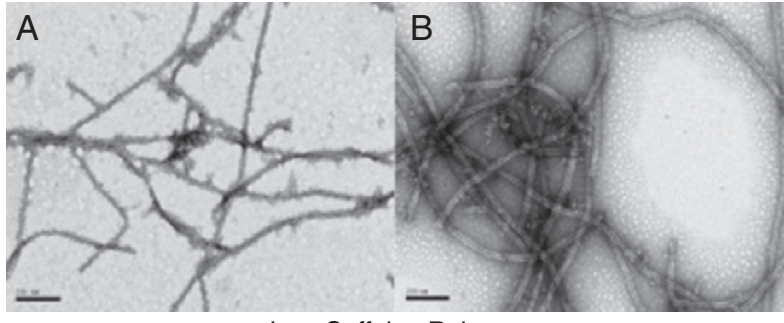

Low Caffeine Release

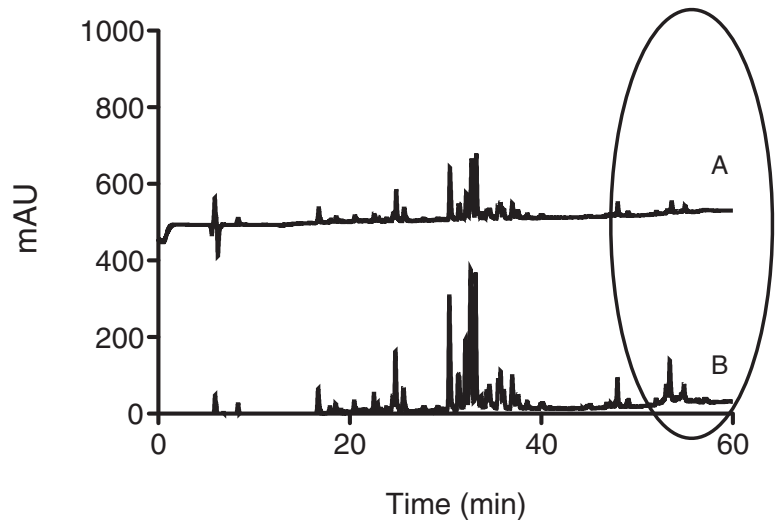

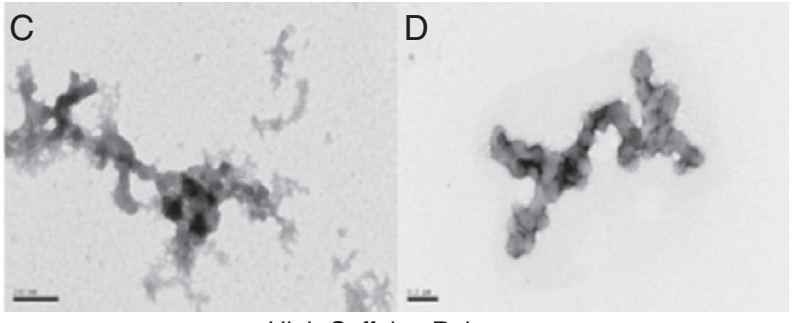

High Caffeine Release

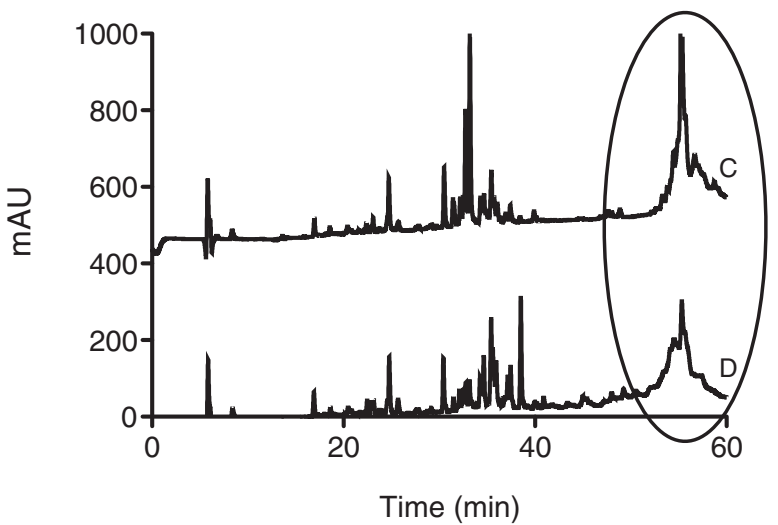

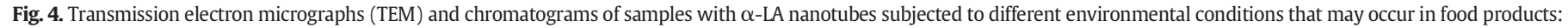

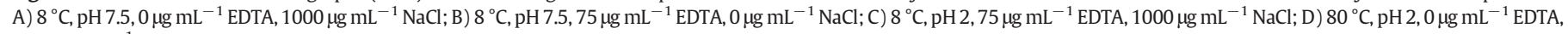
$1000 \mu \mathrm{g} \mathrm{mL}{ }^{-1} \mathrm{NaCl}$. Scale bar of the images is $200 \mathrm{~nm}$.

After neglecting the insignificant terms $(p>0.10)$, the fitted equation which describes the \% $\mathrm{Caf}_{\text {free } \max }$ released from nanotubes is the following $\left(r^{2}=0.8327\right.$ and $r^{2}$ adjusted $\left.=0.7555\right)$ :

$$
\begin{aligned}
\% \mathrm{Caf}_{\text {free } \max }= & (79.40 \pm 1.78)+(11.85 \pm 1.99) \cdot T \\
& +(-12.46 \pm 1.99) \cdot p H+(6.72 \pm 1.99) \cdot T \cdot p H \\
& +(-7.10 \pm 1.99) \cdot T \cdot E D T A+(-4.78 \pm 1.99) \cdot p H \cdot E D T A \\
& +(7.04 \pm 1.99) \cdot T \cdot p H \cdot E D T A
\end{aligned}
$$

The model was statistically significant $(p<0.10)$, and the lack of fit was not significant $(p>0.10)$ (Table 2$)$. The relatively good $r^{2}$ value $\left(r^{2}=\right.$ 0.8327 and $r^{2}$ adjusted $\left.=0.7555\right)$ indicated a good correlation between the adjusted and predicted values, which supports the statistical validity and significance of the equation obtained.

The large values of coefficients for the terms T and pH (Eq. (6)) evidence their effect on $\% \mathrm{Caf}_{\text {free } \max }(p<0.05)$. $\mathrm{NaCl}$ did not have any significant $(p>0.10)$ effect on \%Caf free max. The interaction of EDTA with T and $\mathrm{pH}$ had a significant effect on $\%$ Caf free max $(p<0.05)$. Fig. 5 demonstrated the effect of interactions between T, pH, and EDTA on \% Caf free max. In the absence of EDTA (Fig. 5A), the effect of T on \%Caf free max was intense, with the amount of free caffeine increasing with increasing

Table 2

Analysis of variance (ANOVA) for the results of the fractional factorial design at 2 levels (Box, Hunter, and Hunter $2^{4}$ type, $R=$ FULL) $\left(r^{2}=0.8327, r^{2}\right.$ adjusted $\left.=0.7555\right)$.

\begin{tabular}{llllll}
\hline Factor & $\mathrm{SS}^{\mathrm{a}}$ & $\mathrm{DF}^{\mathrm{b}}$ & $\mathrm{MS}^{\mathrm{c}}$ & $\mathrm{F}$ & $p$ \\
\hline $\mathrm{T}$ & 2245.101 & 1 & 2245.101 & 35.40137 & 0.009494 \\
$\mathrm{pH}$ & 2482.282 & 1 & 2482.282 & 39.14129 & 0.008240 \\
$\mathrm{~T} \cdot \mathrm{pH}$ & 721.863 & 1 & 721.863 & 11.38252 & 0.043289 \\
$\mathrm{~T} \cdot \mathrm{EDTA}$ & 805.850 & 1 & 805.850 & 12.70686 & 0.037695 \\
$\mathrm{pH} \cdot$ EDTA & 365.670 & 1 & 365.670 & 5.76598 & 0.095767 \\
$\mathrm{~T} \cdot \mathrm{pH} \cdot$ EDTA & 793.972 & 1 & 793.972 & 12.51956 & 0.038410 \\
Lack of fit & 1299.458 & 10 & 129.946 & 2.04902 & 0.301762 \\
\hline Pure error & 190.255 & 3 & 63.418 & & \\
\hline Total SS & 8904.451 & 19 & & & \\
\hline
\end{tabular}

${ }^{\mathrm{a} S S}$, sum of squares, ${ }^{\mathrm{b}} \mathrm{DF}$, degrees of freedom, ${ }^{\mathrm{c}} \mathrm{MS}$, mean squares.

$p<0.10$ was considered significant. temperatures, for all the $\mathrm{pH}$-values assayed. Free caffeine also increased by reducing $\mathrm{pH}$, for all the $\mathrm{T}$ assayed, but the effect was less intense than that observed with T. Graveland-Bikker (2005) just explained that $\alpha$-LA nanotubes synthesised in the presence of $\mathrm{Ca}^{2+}$ are resistant to mild heat treatments like a pasteurization process. However, they could not resist longer heating processes and high temperatures $\left(>70^{\circ} \mathrm{C}\right)$. The pH effect could be explained by an increase in the net charge of the building blocks at low $\mathrm{pH}$, which could cause an increase in electrostatic repulsion leading to the nanotubes' disassembly (Graveland-Bikker, 2005).

Introducing EDTA in the release solution (Fig. 5B and C) increased the effect of $\mathrm{pH}$ at low $\mathrm{T}$, being \%Caf free max clearly higher at low $\mathrm{pH}$. At high $\mathrm{T}$, the effect of the other parameters could not be seen probably because the nanotube stability was so low that other effects could be neglected.

It is interesting to note that the interaction of EDTA with $\mathrm{T}$ and $\mathrm{pH}$ had a substantial impact on the nanotubes' stability and caffeine release, resulting in a significant $(p<0.10)$ effect on \%Caf free max (Table 2$)$. At $\mathrm{pH} 7.5$ the effect of EDTA was small, for all the T assayed (Fig. 5F). However, free caffeine increased by increasing the concentration of EDTA when $\mathrm{pH}$ was lowered to 4.8 (Fig. 5E) and, more intensely, to $\mathrm{pH} 2$ (Fig. 5D), at low T. The effect of EDTA at high T was probably masked by the significant effect of these temperatures on nanotube's disassembly.

At high $\mathrm{pH}$ values, EDTA predominates in its fully deprotonated form $\left(\right.$ EDTA $\left.^{4-}\right)$. EDTA ${ }^{4-}$ can chelate or complex metal ions in 1:1 metal-toEDTA complexes (Singh, 2007). In our experimental units, the ratio of $\mathrm{Mn}^{2+}$ :EDTA was at least 5.33 (mol:mol). So the excess of $\mathrm{Mn}^{2+}$ could prevent nanotube disassembly caused by the chelating activity of EDTA. At low pH values, the metal-EDTA complexes become unstable because $\mathrm{H}^{+}$competes with the metal ions for the EDTA, predominating the fully protonated form $\mathrm{H}_{6}$ EDTA $^{2+}$ (Harris, 2013). Nevertheless, the presence of chelating agents like EDTA can induce structural changes in $\mathrm{Ca}^{2+}$-binding proteins like $\alpha$-LA, due to electrostatic repulsion between molecules of similar charge (Stemmer \& Klee, 1990). So, at low $\mathrm{pH}$ values, protonated $\mathrm{H}_{6}$ EDTA $^{2+}$ may contribute to enhance the effect of $\mathrm{pH}$ on the nanotube disassembly due to repulsion between positively charged groups. 

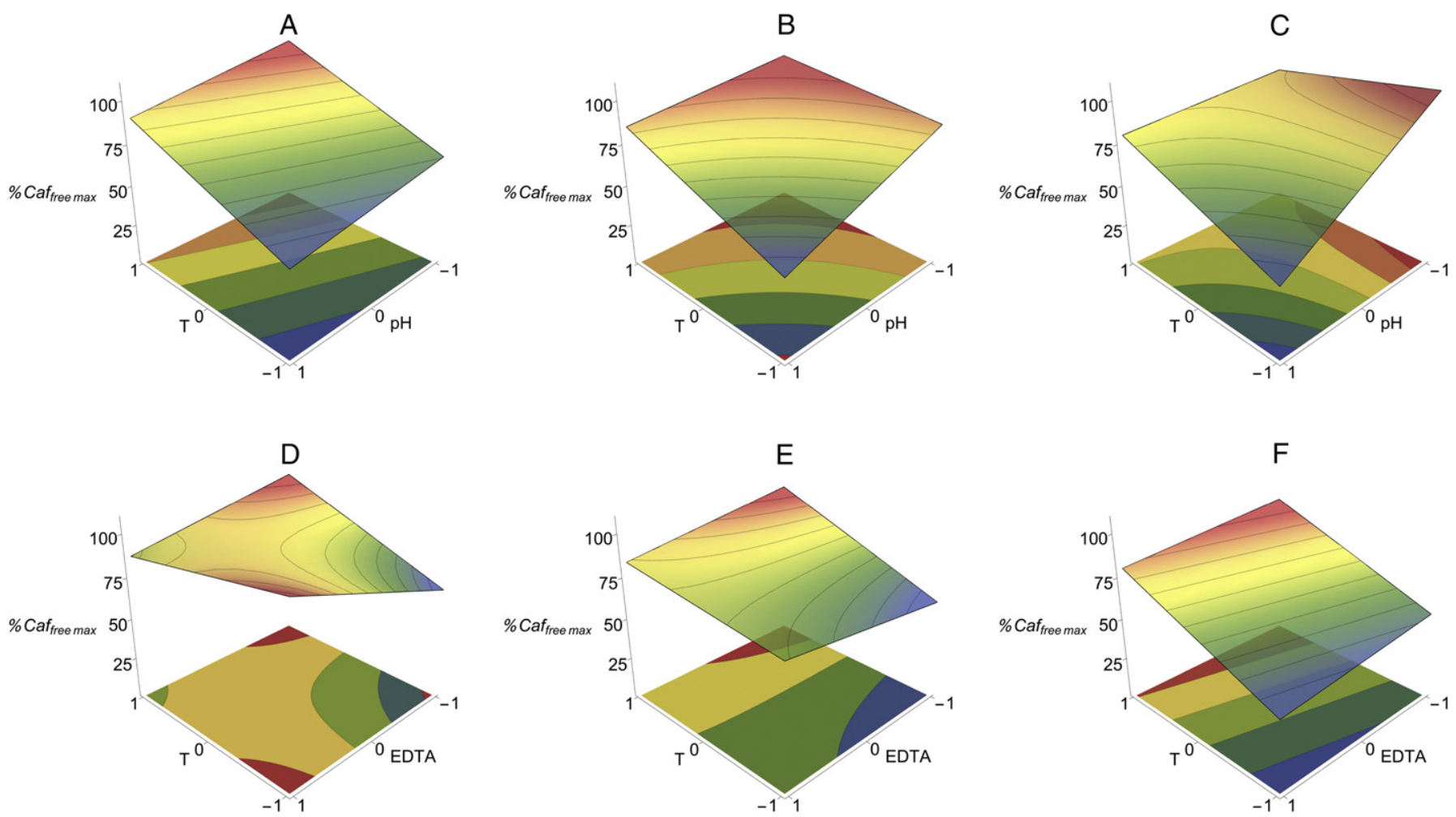

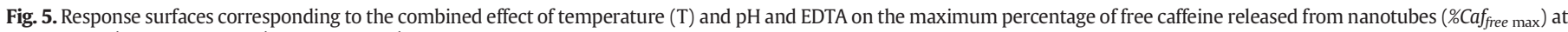
A) $0 \mu \mathrm{g} \mathrm{mL}-1$, B) $37.5 \mu \mathrm{g} \mathrm{mL}{ }^{-1}$, C) $75 \mu \mathrm{g} \mathrm{mL} \mathrm{m}^{-1}$ of EDTA, D) $\mathrm{pH} 2$, E) pH 4.8, and F) pH 7.5, according to the Eq. (6).

Within the domain evaluated, the predicted minimum $\%$ Caf free max was 43.65 (i.e. $~ 56.35 \%$ remained retained) and occurred at $8{ }^{\circ} \mathrm{C}$, $\mathrm{pH} 7.5$ and $75 \mu \mathrm{g} \mathrm{mL} \mathrm{m}^{-1}$ of EDTA. Our experimental results confirmed the prediction. Thus, the \% Caf free max values obtained experimentally under these conditions were $45.42 \pm 3.73$ and $47.83 \pm 3.57$ at 0 and $1000 \mu \mathrm{g} \mathrm{mL}{ }^{-1}$ of $\mathrm{NaCl}$, respectively. Therefore, the conditions that will help to maintain caffeine encapsulated into $\alpha$-LA nanotubes, during food processing and storing until their consumption, are refrigeration temperatures at neutral or alkaline $\mathrm{pH}$. In acidic conditions the absence of chelating agents would be preferable.

\section{Conclusions}

$\alpha$-LA nanotubes resulted highly stable during a freeze-drying process, which could be very useful considering their preservation and future commercialization. Also, $\alpha$-LA nanotubes seem to be highly effective in caffeine encapsulation, achieving values near of $100 \%$ of encapsulation efficiency and close to $10 \%$ of loading capacity. Nanotubes' structure did not appear to be damaged by the presence of caffeine so that they could maintain their functionality as a thickener agent. There was a clear correlation between those conditions where nanotubes appeared more damaged and higher caffeine release ratios. An equation was developed using a $2^{4}$ full-factorial design to determine the percentage of caffeine that remains trapped into $\alpha$-LA nanotubes as a function of environmental conditions that may occur in food products.

\section{Acknowledgements}

Clara Fuciños gratefully acknowledge her Post-Doctoral grant (I2C 2014) from Consellería de Cultura, Educación e Ordenación Universitaria (Xunta de Galicia, Spain). Pablo Fuciños gratefully acknowledges his Marie Curie COFUND Postdoctoral Research Fellowship (Project No: 600375. NanoTRAINforGrowth - INL Fellowship programme in nanotechnologies for biomedical, environment and food applications). This study was supported by the Fundação para a Ciência e a Tecnologia (FCT) under the scope of the strategic funding of UID/BIO/04469/2013 unit and COMPETE 2020 (POCI-01-0145FEDER-006684), and the Project RECI/BBB-EBI/0179/2012 (FCOMP-010124-FEDER-027462).

\section{References}

Abbasi, A., Emam-Djomeh, Z., Mousavi, M. A. E., \& Davoodi, D. (2014). Stability of vitamin D3 encapsulated in nanoparticles of whey protein isolate. Food Chemistry, 143, 379-383.

Arroyo-Maya, I. J., Rodiles-López, J. O., Cornejo-Mazón, M., Gutiérrez-López, G. F., Hernández-Arana, A., Toledo-Núñez, C., \& Hernández-Sánchez, H. (2012). Effect of different treatments on the ability of a-lactalbumin to form nanoparticles. Journal of Dairy Science, 95(11), 6204-6214.

Augustin, M. A. (2003). The role of microencapsulation in the development of functional dairy foods. Australian Journal of Dairy Technology, 58(2), 156-160.

Bagheri, L., Madadlou, A., Yarmand, M., \& Mousavi, M. E. (2013). Nanoencapsulation of date palm pit extract in whey protein particles generated via desolvation method. Food Research International, 51(2), 866-871.

Belscak-Cvitanovic, A., Komes, D., Karlovic, S., Djakovic, S., Špoljaric, I., Mršic, G., \& Ježek, D. (2015). Improving the controlled delivery formulations of caffeine in alginate hydrogel beads combined with pectin, carrageenan, chitosan and psyllium. Food Chemistry, 167, 378-386.

Bohannon, R. (2008). Food products having caffeine incorporated therein. U.S. Patent Appl. No. 11/961,656. Google Patents.

Bourbon, A. I., Cerqueira, M. A., \& Vicente, A. A. (2016). Encapsulation and controlled release of bioactive compounds in lactoferrin-glycomacropeptide nanohydrogels: Curcumin and caffeine as model compounds. Journal of Food Engineering, 180, 110-119.

Chen, L., \& Subirade, M. (2007). Effect of preparation conditions on the nutrient release properties of alginate-whey protein granular microspheres. European Journal of Pharmaceutics and Biopharmaceutics, 65(3), 354-362.

Chen, L., Remondetto, G. E., \& Subirade, M. (2006). Food protein-based materials as nutraceutical delivery systems. Trends in Food Science and Technology, 17(5), 272-283.

Dumitriu, S., \& Popa, V. (2013). Polymeric biomaterials: Medicinal and pharmaceutical applications volume 2. Boca Raton, FL (USA): CRC Press.

Estévez, N. (2015). Integrative processes for the valorisation of bovine whey proteins through the production of bioactive peptides and heat-induced gels, and their use as functional ingredients. (Doctoral thesis) Ourense Spain: University of Vigo. 
Fuciños, C., Guerra, N. P., Teijón, J. M., Pastrana, L. M., Rúa, M. L., \& Katime, I. (2012). Use of poly( $\mathrm{N}$-isopropylacrylamide) nanohydrogels for the controlled release of pimaricin in active packaging. Journal of Food Science, 77(7), N21-N28.

Graveland-Bikker, J. (2005). Self-assembly of hydrolysis $\alpha$-lactalbumin into nanotubes. (Doctoral thesis) Utrecht, The Netherlands: University of Utrecht ISBN9090198555; 9789090198552)

Graveland-Bikker, J. F., Ipsen, R., Otte, J., \& De Kruif, C. G. (2004). Influence of calcium on the self-assembly of partially hydrolyzed $\alpha$-lactalbumin. Langmuir, 20(16) 6841-6846.

Gudas, V. V., Reed, M. A., Schnell, P. G., Tyrpin, H. T., Russell, M. P., \& Witkewitz, D. L (2000). Method of controlling release of caffeine in chewing gum. U.S. Patent No. 6,165,516. Google Patents.

Gunasekaran, S., Ko, S., \& Xiao, L. (2007). Use of whey proteins for encapsulation and controlled delivery applications. Journal of Food Engineering, 83(1), 31-40.

Harris, D. C. (2013). EDTA titrations. In D. C. (Ed.), Exploring chemical analysis (pp. 278) (5th Ed. ed.). New York (USA): W. H. Freeman and Company.

Ipsen, R., \& Otte, J. (2007). Self-assembly of partially hydrolysed $\alpha$-lactalbumin Biotechnology Advances, 25(6), 602-605.

Kolayli, S., Ocak, M., Küçük, M., \& Abbasoglu, R. (2004). Does caffeine bind to metal ions? Food Chemistry, 84, 383-388.

Langer, R., \& Peppas, N. A. (2003). Advances in biomaterials, drug delivery, and bionanotechnology. AICHE Journal, 49(12), 2990-3006.

López-Rubio, A., \& Lagaron, J. M. (2012). Whey protein capsules obtained through electrospraying for the encapsulation of bioactives. Innovative Food Science and Emerging Technologies, 13, 200-206 (JANUARY).

Madadlou, A., Jaberipour, S., \& Eskandari, M. H. (2014). Nanoparticulation of enzymatically cross-linked whey proteins to encapsulate caffeine via microemulsification/heat gelation procedure. LWT - Food Science and Technology, 57(2), 725-730.
Mohammadi, A., Jafari, S. M., Esfanjani, A. F., \& Akhavan, S. (2016). Application of nanoencapsulated olive leaf extract in controlling the oxidative stability of soybean oil. Food Chemistry, 190, 513-519.

Moraru, C. I., Panchapakesan, C. P., Huang, Q., Takhistov, P., Liu, S., \& Kokini, J. L. (2003). Nanotechnology: A new frontier in food science. Food Technology, 57(12), 24-29.

Nedovic, V., Kalusevic, A., Manojlovic, V., Petrovic, T., \& Bugarski, B. (2013). Encapsulation systems in the food industry. In S., P., N. G., \& V. T. (Eds.), Advances in food process engineering research and applications (pp. 229) (1st ed.). New York: Springer.

Pridgen, E. M., Alexis, F., Langer, R. S., \& Farohkzad, O. C. (2009). Biodegradable, targeted polymeric nanoparticle drug delivery formulation for cancer therapy. In K., \& I. L. (Eds.), Methods in bioengineering nanoscale bioengineering and nanomedicine (pp. 197) (1st ed.). Boston/London: Artech House.

Sadeghi, R., Kalbasi, A., Emam-jomeh, Z., Razavi, S. H., Kokini, J., \& Moosavi-Movahedi, A.A. (2013). Biocompatible nanotubes as potential carrier for curcumin as a model bioactive compound. Journal of Nanoparticle Research, 15(11), 1931-1941.

Singh, G. (2007). Precipitation from homogeneous medium. In G. (Ed.), Chemistry of lanthanides and actinides (pp. 82) (1st ed.). New Delhi (India): Discovery Publishing House.

Sobel, R., Gundlach, M., \& Su, C. (2014). Novel concepts and challenges of flavor microencapsulation and taste modification. In A., N., A., \& R. (Eds.), Microencapsulation in the food industry: A practical implementation guide (pp. 421) (1st ed.). San Diego (USA): Elsevier.

Stemmer, P., \& Klee, C. B. (1990). Electrostatic repulsion between molecules of like charge can be misinterpreted as binding. FEBS Letters, 276(1-2), 71-74.

Vijayaragavan, S., Vino, S., Kalyani Rath, S., Mishra, B., Ghosh, A. R., \& Jayaraman, G. (2014). Controlled release of a water soluble drug, metoprolol succinate, by a-lactalbumin microparticles. International Journal of Pharmacy and Pharmaceutical Sciences, 6(1), 762-767. 